\title{
Floods emergency management: the value of potential and actual damage estimation
}

\author{
D. Molinari ${ }^{1}$, F. Ballio ${ }^{1}$ \& S. Menoni ${ }^{2}$ \\ ${ }^{1}$ Dept. of Environmental, Hydraulic, Infrastructures and Surveying \\ Engineering, Politecnico di Milano, Italy \\ ${ }^{2}$ Dept. of Architecture and Planning, Politecnico di Milano, Italy
}

\begin{abstract}
Emergency management (intended here from emergency planning to reaction) is a crucial aspect of risk management, allowing us to handle residual risk. Therefore, its economic convenience is an important piece of information in designing flood risk management strategies. This paper seeks to answer the following questions: How expected damage reduction due to emergency management can be estimated? Which analyses are required? Are there available tools in literature?

In the paper, a framework is provided to describe the process of emergency management and preventive actions leading to damage reduction. The latter are differently handled according to whether they are addressed to reduce the hazard or exposure/vulnerability. The framework is then applied to a real case study. Results suggest that damage reduction estimation is possible, even though available models still require further improvement, in terms of transferability and required data/knowledge. On the other hand, results show the utility of the information supplied by this kind of analysis for decision makers.

Keywords: emergency management, EWS, depth-damage curves, actual damage, floods directive.
\end{abstract}

\section{Introduction}

Looking at the past, history teaches us that where a risk is present, it is impossible to totally protect communities from the likelihood of a disastrous event even if proper mitigation measures are implemented; as a consequence, a "residual risk" always exists which affects exposed systems. Emergency 
management (intended here from emergency planning to reaction) allows us to handle residual risk; impacts can be decreased if people are aware of upcoming events and are prepared to react. For this reason, the role of emergency management became increasingly important in the last few decades $[1,2]$

Although the prime purpose of emergency management is to save life, which ideally always justifies the adoption of emergency management strategies, this paper focuses upon the economic savings caused by emergency management, with particular attention on floods. Economic convenience is a critical piece of information in defining flood management policies; the recent Floods Directive [3], for example, explicitly requires us to take account of costs and benefits in the design of flood risk management plans.

When damage to people is not considered, some questions arise: How expected damage reduction can be estimated? Which analyses are required? Are there available tools in literature? This paper seeks to answer these questions.

A methodology is supplied and damage reduction is actually estimated for a case study. Despite all the uncertainties that presently affect case study's results, the implementation of the methodology allows us to take a further step forward in the comprehension of the problem at stake; on the one hand, it allows us to identify which are the current difficulties in applying the methodology and, as a consequence, which are the priorities for future research. On the other hand but even more important, it allows us to understand what the value of damage reduction estimation is in terms of knowledge supplied to emergency managers. Indeed, a principle is maintained in the paper according to which good emergency management should assemble feasible and effective strategies to cope with the event which are specific for the context under investigation. The evaluation of expected damage reduction is thus a critical piece of information to adjust/design emergency plans, by defining better response strategies.

The paper is organized as follows: In section 2 a framework is provided to describe the process and preventive actions leading to damage reduction. The framework is linked to available modeling approaches for the estimate of expected damage reduction. The case study is presented in section 3 which explains how damage reduction can be estimated in practice; results are then discussed, with particular attention on the utility supplied by the assessment in terms of available knowledge for emergency managers. A critical analysis of the methodology is supplied in section 4 . Finally, section 5 reformulates findings from previous sections in order to answer the original questions of the paper.

\section{Emergency management in case of flood: The aim of reducing potential damage}

Figure 1 depicts the emergency management process as conceived in this paper:

- When a flood is monitored or forecasted, civil protection makes choices, ideally according to what has been previously arranged in the emergency plan; these choices regard both warning and preventive measures which aim at reducing exposure, vulnerability and flood intensity. 
- Once the warning has been issued, lay people react to it and implement, in turn, preventive measures. The latter are addressed to reduce exposure and/or vulnerability; literature highlights that people reaction depends on both warning features and social vulnerability $[2,4,5]$;

- The extent of items at risk (after preventive measures have been implemented), their vulnerability (from all its perspectives: social, institutional, functional and physical) and flood intensity concur then to define expected damages.

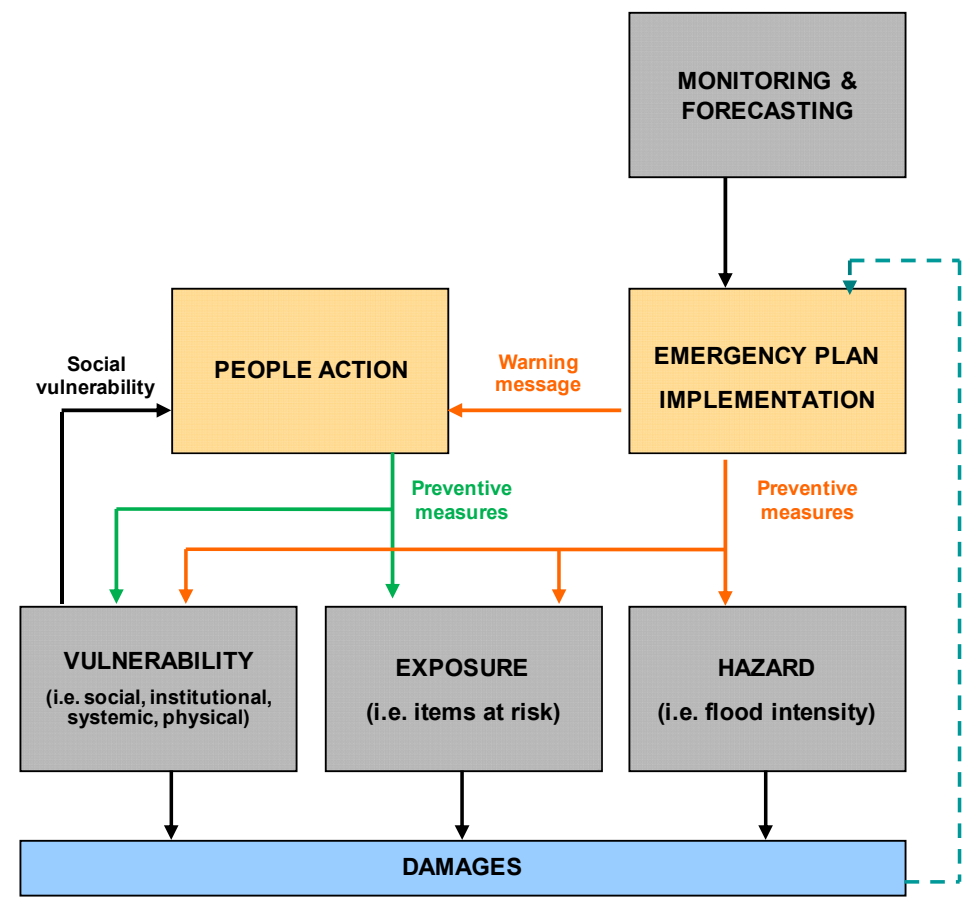

Figure 1: The emergency process, as conceived in this paper. Coloured arrows represent preventive measures implemented during emergency, whose effects need to be modelled.

Evaluating damage reduction due to emergency management is equivalent to modelling the effect (on expected damages) of preventive measures implemented during the event, by both civil protection and lay people. Such an assessment can be used then to adjust emergency plans; this is pointed out in fig. 1 by the backgoing dotted arrow which stresses how assessment's results can influence initial choices.

Referring to the most quoted terminology in available literature [6-8] the problem of assessing damage reduction can be viewed in terms of the estimate of actual versus potential damages where potential damages are those damages that might happen when no emergency management exists; actual damages are, 
instead, damages that would really happen after preventive measures are adopted.

Improving potential damages models is beyond the scope of this paper. A variety of tools are already available in literature [9-12]. In a nutshell, potential damages are usually estimated by means of depth-damage curves (which supply expected damage to affected items against water depth), field surveys or back analyses of damage data. Focusing instead on preventive measures, fewer tools are available [13-16]. In this paper, the effect of preventive measures on potential damages is differently modeled according to the objective of the actions; indeed two kinds of preventive actions can be put in place (fig. 2):

- those reducing the intensity of the hazard (i.e. levees rising and reinforcement, bridge gates, temporary dikes, etc.);

- those aiming at limiting exposure and vulnerability (e.g. moving contents, temporary water gates, etc.).

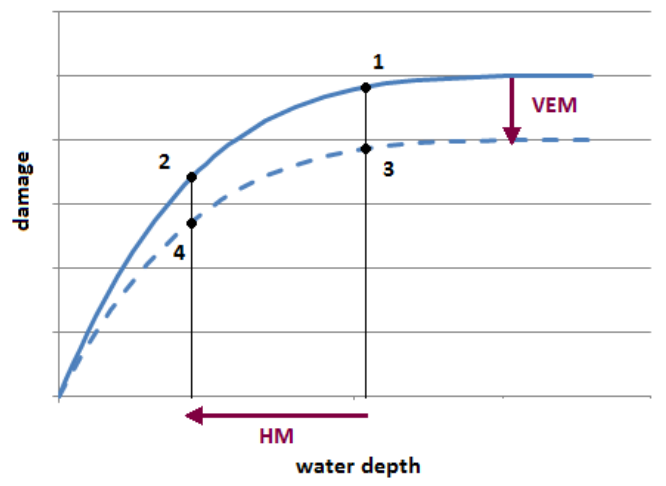

Figure 2: $\quad$ Effect of hazard mitigation (HM) and vulnerability and exposure mitigation (VEM) on potential damages.

In both cases, effectiveness depends on the level of preparedness as well as the available time for implementation; still, the effect on the potential damage curve is different. In the first case, preventive actions imply that, for a given event, the water depth in the flooded area decreases; accordingly, a shift occurs on the $\mathrm{X}$-axis (identified by HM in fig. 2) so that if 1 represents the starting point for potential damages, the new value for damage (i.e. actual damage), after HM preventive actions, is 2. Otherwise, it is possible to explain the effect of actions on exposure and vulnerability as another depth-damage curve describing actual damages. The latter can be interpreted as the consequence of a shift (identified by VEM in fig. 2) in the potential damage curve so that, for a certain water depth, damage is less because of exposure and/or vulnerability reduction. Accordingly, if 1 represents the starting point for potential damages, the new value for damage (i.e. actual damage), after VEM preventive actions, is 3 . Clearly, the combination of the two kinds of action brings the original damage to point 4. 
Actual damage estimation requires the evaluation of both the effects. As a matter of fact, whilst the effect of preventive actions on hazard reduction can always be estimated by means of a hydraulic analysis, the evaluation of the consequence of preventive actions on exposure and vulnerability requires specific models and is still an open question $[2,17]$. In section 3 , a case study is supplied to describe how such an assessment can be carried out with available models. Both in the assessment of potential and actual damages, all types of damages (i.e. direct/indirect, tangible/intangible) and exposed items should be ideally accounted for. Nevertheless, damage to people is not considered in this paper, the objective being the evaluation of the economic benefit of emergency management.

\section{Case study}

The scope of this section is to describe how actual damages can be estimated in practice. Potential damages are first estimated; then the effect of preventive actions on damage reduction is assessed.

The case under investigation is the town of Sondrio, in the Italian Alpine region, where flood risk is induced by the River Mallero. It is important to clarify that the case study does not aim at supplying an exact estimate of potential and actual damages; this would be challenging in the Italian context where specific tools and data for their estimation are not available. On the contrary, the objective is to highlight which tools are available for damage estimation, which kind of knowledge such an estimate could supply (in a plausible case) and how this knowledge could be used to improve emergency management. For this reason, available tools from other countries are here implemented, being aware that their fitness with Italian context must still be proved and represents a priority for future research; as a result of the exercise, the following results are however considered reliable.

Emergency management in Sondrio is responsibility of local authorities who arranged for an emergency plan to deal with flood events. The plan sets preventive actions to be implemented by both civil protection and lay people after a warning is issued. The warning system is based on river discharge thresholds; once flood forecasts exceed one of them, the corresponding warning level is implemented. The plan schedules two main preventive measures in case of warning:

- the use of temporary gates (from now on called "bridge gates") to close river bank openings at bridges, which is done by civil protection;

- people-individuals' actions like moving contents, turning-off gas, sandbagging, etc.

\subsection{Potential damages assessment}

Potential damages estimation in Sondrio focused on the following types of damage:

- $\quad$ physical/direct damage to buildings; 
- $\quad$ physical/direct damage to infrastructures;

- emergency costs, defined here as the cost required us to face the emergency.

Indirect damages due to business/services disruption as well as intangible damages were not considered in the present study.

According to section 2, physical/direct damage to buildings and infrastructures was calculated by means of available depth-damage curves; specifically, curves by the US Army Corps of Engineers [19] were implemented for buildings while the Dutch Standard Method [20] was adopted for infrastructures. The two methods were selected taking into account their transferability to the context under investigation that is the correspondence between hazard and vulnerability parameters considered in the methods, the vulnerability of exposed items and the available knowledge about the hazard. A literature review highlighted that few tools are instead available for emergency costs estimation; here the model suggested by Penning-Rowsell et al. [6] was implemented which estimates emergency costs as a fixed percentage of the value of physical/direct damage to buildings equal to $10 \%$. The model was validated with data coming from the local database RaSDa (acronym of "Sistema per la Raccolta delle Schede Danni", Italian translation for "System to collect damage data") [18]. Fig. 3-serie 1 displays assessment results in terms of the extent of potential damages against river discharge.

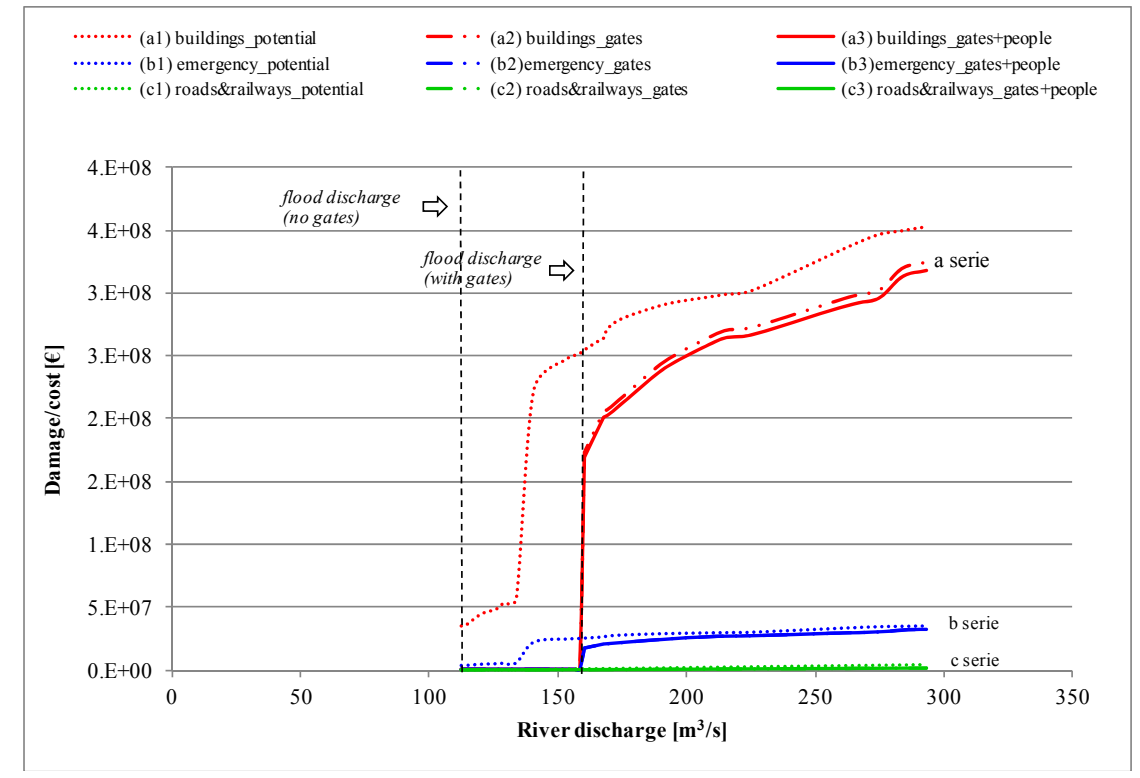

Figure 3: Results of damage assessment: potential vs. actual damages; figure distinguishes between different classes (referred to as a, b, c) and between the effect of bridge gates only and the joint effect of bridge gates and people actions (referred to as 2, 3). 


\subsection{Actual damages assessment}

According to section 2, actual damages estimation requires to assess the effect of the preventive measures scheduled in the emergency plan on potential damages. As regards to bridge gates, an hydraulic analysis was performed (not reported here [18]) given that the effect of bridge gates is to reduce the hazard by increasing the bankfull discharge of the river (see section 2). According to the analysis, the latter increases up to $160 \mathrm{~m} 3 / \mathrm{s}$.

People actions was modelled instead as a shift in potential depth-damage curves (see section 2). In detail, a fixed percentage of potential damages was considered for every water depth value. This percentage is equal to $4.5 \%$, according to the value suggested by [6] for the warning context observed in Sondrio. Fig. 3 reports the comparison between results for potential and actual damages estimation. To be noted that the figure distinguishes between the effect of bridge gates only and the joint effect of bridge gates and people actions.

\subsection{Utility of damage assessment results}

Analyses carried out in the previous section allow to infer useful information regarding both the system under investigation, its (economic) convenience and its functioning during emergency. Useful knowledge derives initially from potential damages assessment; in detail, fig. 3 picks out that:

- first, physical/direct damage to buildings is significant and represents the major component of the total damage;

- $\quad$ second, physical/direct damage to single infrastructures is less relevant than physical/direct damage to buildings; specifically, damage to infrastructures is, on average, four orders of magnitude less than that to buildings.

Regarding the former point, it must be observed that this evidence does not depend on "emergency management" but it is linked to potential damages; in other words, to reduce damage to buildings, priority must be given to mitigation actions "in time of peace" (i.e. before the event strikes) which would aim at reducing buildings vulnerability (e.g. buildings codes), their exposure (e.g. planning) as well as the hazard (e.g. levees, detention basins). With respect to the second point, instead, the result is sensible, considering that damages to infrastructures are usually mainly indirect (e.g. damage due to the disruption of traffic, economic activities, etc., see section 4).

Actual damages assessment allows instead to infer useful information about emergency management economic convenience as well as on emergency management planning. Fig. 3 puts into evidence that damage reduction due to preventive actions is mainly due to bridge gates. Such an evidence suggests the more suitable emergency strategy too. Indeed, given that benefit from bridge gates is significant and actually with no costs (but for indirect damages due to traffic/business disruption, not computed here, see section 4) emergency managers should act "for safety" in their adoption. In other word, they should always adopt bridge gates when a flood cue is observed (forecasted), even if uncertainty is high. Moreover, it should be borne in mind that, even if damage to 
people is not evaluated here, the main objective of emergency management should always be safe life. In accordance with this, limiting people access to flooded areas sounds sensible as road users represent up to half of the deaths during floods [21, 22]; from this perspective, the precautionary use of bridge gates is wise. Otherwise, fig. 3 highlights that damage reduction due to people action is limited. Thus, considering also that major costs can occur if false warnings are frequent (also in terms of loss of trust, wolf-crying syndrome, etc.), emergency managers may decide to act "against safety" in warning people, waiting until more certain forecast is available.

\section{Critical discussion}

Besides inherent uncertainties of damage models [23], the estimation of direct damages suffer from two main limitations. The first relates to infrastructures; present damage estimation does not take into account damage to accessories and installations (e.g. bridges, tunnels, water tanks, purification plants, control room, etc.) which, instead, can be relevant [18]. However, authors are not aware of parametric models which are able to adequately estimate damage to accessories and installation.

A second limitation relates instead to emergency costs; even though costs have been set equal to $10 \%$ of damage to buildings, validation with RaSDa data (not reported here [18]) suggests that they could be much more significant. This is especially important when emergency costs are compared with emergency benefits. Fig. 3 shows, for example, that emergency costs (i.e. the "b" serie) and damage reduction to buildings (i.e. the difference a1-a3), which represents the main benefit, are of the same order in the case under investigation. However, because of the above modelling uncertainty, it is possible that emergency costs are higher than benefits, bringing to emergency management ineffectiveness. Thus, improved models to assess emergency costs are required.

When actual damages estimation is considered, the main problem regards instead damage reduction due to people actions which was modelled as a fixed shift in potential depth-damage curves; this is the simplest method but it is worthy to note that, when data are available, assessment methods based on the modelling of people behaviour would represent a more suitable choice [16, 24].

Finally, as regards neglected types of damages, it is sensible that the inclusion of indirect and intangible damages severely affect emergency management convenience, as derived from the case study. From an economic point of view, it is evident that potential and actual damages change when indirect damages are considered. For example, indirect damages due to bridge gates can be relevant given that the economic activity of the area can suffer from traffic disruption. On the contrary, also indirect benefits can be significant; in fact bridge gates allow us to avoid the inundation of the city for $\mathrm{Q}<160 \mathrm{~m}^{3} / \mathrm{s}$ preventing not only direct damages but also indirect damages to enterprises (i.e. loss of income).

On the other hand, it is clear that emergency management convenience goes beyond economic considerations. When intangibles are considered, convenience increases given that emergency management enables us to save lives, 
memorabilia, cultural heritage, etc. [16, 17]. However, available tools for indirect and intangible damage estimation seem unsuitable for practical and systematical purposes and require specific knowledge and usually unavailable data.

\section{Conclusion}

This paper analyzes and implements available tools for damage assessment in a pragmatic framework to describe and assess damage reduction due to emergency management; the framework is then applied to a real case study.

The conceptualization of the problem at stake represents the main strength of the paper; section 2 supplies a pragmatic framework to describe the emergency management process and preventive measures leading to damage reduction and suggests how damage reduction modeling should be approached as the objective of preventive actions changes (i.e. reducing hazard vs. reducing exposure/vulnerability).

The case study proves that damage reduction estimate is possible even though present models still require further improvement and must be adapted to the specific context under investigation; this strongly influence present accuracy. At the same time, the case study points out that assessment results supply useful information, not only in terms of economic convenience of emergency management but also in terms of the comprehension of the system under investigation and its functioning during emergency. From this perspective, this paper supports and encourages present efforts of the research community in improving damage models.

\section{References}

[1] Romang, H., Zappa, M., Hilker, N., Gerber, M., Dufour, F., Frede, V., Berod, D., Oplatka, M., Hegg, C. \& Rhyner, J. IFKIS-Hydro: an early warning and information system for floods and debris flows. Nat Hazards 56, pp. 509-527, 2010.

[2] Modelling the damage reducing effects of flood warnings; FLOODsite project, Report T10-07-12. Online. www.floodsite.net

[3] Directive 2007/60/EU of the European Parliament and of the Council of 23 October 2007 on the assessment and management of flood risks, Official Journal of the European Union, 2007.

[4] Handmer, J.W. \& Ord, K.D. Flood warning and response. Flood warning in Australia, ed. Smith, D.I. \& Handmer, J.W, Centre for Resource and Environmental Studies: Canberra, pp. 235-257, 1986.

[5] Sorensen, J. \& Mileti, D., Warning and evacuation: answering some basic questions. Ind Crisis Q 2(3-4), pp. 195-210, 1989.

[6] Penning-Rowsell, E.C., Johnson, C., Tunstall, S., Tapsell, S., Morris, J., Chatterton, J., Coker, A.\& Green, C., The benefits of flood and coastal risk management: a manual of assessment techniques, Middlesex University Press: London, 2005. 
[7] Disaster loss assessment - Guidelines, State of Queensland and Commonwealth of Australia, 2002.

[8] Framework for estimating national economic development benefits and other beneficial effects of flood warning and preparedness systems, IWR Report 94-R-3. Online. www.iwr.usace.army.mil/docs/iwrreports/94-R3.pdf

[9] Evaluating flood damages: guidance and recommendations on principles and methods; FLOODsite project, Report T09-06-01. Online. www.floodsite.net

[10] Smith, D.I. Flood damage estimation-a review of urban stage damage curves and loss function. Water SA, 20(3), pp. 231-238, 1994.

[11] Thieken, A.H., Muller, M., Kreibich, H. \& Merz, B.: Flood damage and influencing factors: new insights from the august 2002 flood in Germany. Water Resour. Res., 41, doi: 10.1029/2005WR00417, 2005.

[12] Thieken, A.H., Ackermann, V., Elmer, F., Kreibich, H., Kuhlmann, B., Kunert, U., Maiwal, H., Merz, B., Muller, M., Piroth, K., Schwarz, J., Schwarze, R., Seifert, I. \& Seifert, J. Methods for the evaluation of direct and indirect flood losses. Proc. of the 4th Int. Symp. On flood defense, Toronto, Canada, 2008.

[13] Day, H. J.: Flood warning benefit evaluation-Susquehanna River Basin (urban residences), ESSA Technical Memorandum WBTM, Hydro-10, National Weather Service: Silver Spring, 1970.

[14] Chatterton J. B. \& Farrell, S. Nottingham flood warning scheme: Benefit assessment, Report prepared for Severn-Trent Water Authority, Middlesex, U.K., 1977.

[15] Handmer, J. W. \& Smith, D.I.: Adjustment factors for flood damage curves. Journal of Water Resources Planning and Management, 116 (6), pp. 843-846, 1990.

[16] Parker, D., Tapsell, S. \& McCarthy, S.: Enhancing the human benefits of flood warnings. Nat. Hazards 43, pp. 397-414, 2007.

[17] Carsell, K.M., Pingel, N.D. \& Ford, D.T.: Quantifying the benefit of a flood warning system. Natural Hazards Review, 5(3), pp. 131-140, 2004.

[18] Molinari, D.: Flood early warning systems performance: an approach at the warning chain perspective, Politecnico di Milano, $\mathrm{PhD}$ Dissertation: Milan, Italy, 2011.

[19] Generic depth-damage relationships for residential structures with basements, economic guidance memorandum, US Army Corps of Engineering, Economic Guidance Memorandum (EGM) 04-01. Online. planning.usace.army.mil/toolbox/library/EGMs/egm04-01.pdf

[20] Kok, M., Huizinga, H.J., Vrouwenvelder, A.C.W.M. \& Barendregt, A.: Standard Method 2004: damage and casualties caused by flooding. Road and Hydraulic Engineering Institute: Netherlands, 2005.

[21] Gruntfest, E. \& Handmer, J.W. (eds.). Coping with Flash Floods. Vol. 77 NATO Advanced Study Institute, Kluwer Academic Publishers: Dordrecht, 2001. 
[22] Jonkman, S. \& Kelman, I.: An analyses of causes and circumstances of flood disaster deaths. Disasters, 29 (1), pp. 75-97, 2005.

[23] Merz, B., Kreibich, H., Thieken, A. \& Schmidtke, R.: Estimation uncertainty of direct monetary flood damage to buildings. Nat. Hazards Earth Syst. Sci., 4(1), pp. 153-163, 2004.

[24] Molinari, D. \& Handmer, J.W.: A behavioral model for quantifying flood warning effectiveness. J. Flood Risk Manag., 4(1), pp.23-32, 2011. 